\title{
Educação e Direitos Humanos: perspectivas decoloniais desde o litoral norte do Rio Grande do Sul
}

\author{
Education and Human Rights: decolonial perspectives from the north coast \\ of Rio Grande do Sul
}

\begin{abstract}
Thaís Janaina Wenczenovicz Doutora em História/PUCRS.

Docente adjunta/pesquisador sênior da Universidade Estadual do Rio Grande do Sul/UERGS. Professora Titular no Programa de Pós-Graduação em Educação/UERGS. Professora Colaboradora no Programa de Pós-graduação Stricto Sensu em Educação da Universidade Estadual do Paraná- UNIOESTE. Professora Titular no Programa de Pós-Graduação Stricto Sensu em Direitos Fundamentais/UNOESC. Avaliadora do INEP - BNI ENADE/MEC. Membro do Comitê Internacional Global Alliance on Media and Gender (GAMAG)/UNESCO. Líder do Grupo de Pesquisa CNPq/UERGS Direitos Humanos e Justiça: perspectivas decoloniais. t.wencze@terra.com.br
\end{abstract}

\begin{abstract}
Anderson Alves Costa Mestre em Educação na Universidade Estadual do Rio Grande do Sul/ UERGS, Unidade Litoral Norte/Osório. Docente rede pública do estado do Rio Grande do Sul. Membro do Grupo de Pesquisa CNPq/UERGS Direitos Humanos e Justiça: perspectivas decoloniais. anderson-costa@uergs.edu.br
\end{abstract}

Resumo: o estudo busca analisar a relação dialógica entre educação e Direitos Humanos de maneira a sugestionar um currículo escolar intercultural, a ser concebido com assente em uma pedagogia decolonial como práticas insurgentes ao atual currículo em um locus-regional- litoral norte do Rio Grande do Sul. Também reflexiona sobre aos protagonismos educativos em conformidade com os Direitos Humanos no contexto da educação brasileira em face dos processos universalizantes que ocupam grande parte das escolas. Torna-se urgente superar o atual modelo de ensino padronizado/ universalizante que atende precário e parcialmente ou sequer atende às demandas regionais, pois outras noções, conceitos e práticas na contemporaneidade, advindos de locais subalternizados, fazem-se presentes e potencialmente aplicáveis. Utiliza-se do procedimento metodológico bibliográfico-investigativo, acrescido de dados e estatísticas do INEP de Censos Escolares (2015, 2016 e 2017).

Palavras-chave: Decolonialidade. Direitos Humanos. Educação. Litoral Norte do Rio Grande do Sul

Abstract: The study seeks to analyze the dialogical relationship between education and Human Rights in order to suggest an intercultural school curriculum, to be conceived based on a decolonial pedagogy as practices insurgent to the current curriculum in a locus-regional - north coast of Rio Grande do Rio. It also reflects on the educational protagonism in conformity with Human Rights in the context of Brazilian education in the face of the universalizing processes that occupy a large part of schools. It is urgent to overcome the current model of standardized/ universal teaching that meets precarious and partially or does not even meet the regional demands, because other notions, concepts and practices in contemporary times, coming from subalternized places, are 
present and potentially applicable. It uses the bibliographic-investigative methodological procedure, plus data and statistics from INEP of School Censuses (2015, 2016 e 2017).

Key Words: Decoloniality. Human rights. Education. North Coast of Rio Grande do Sul.

\section{Introdução}

Pensar a educação e as práticas escolares para além dos princípios universalizantes tornase necessário em reconhecimento a multidiversidade do Brasil. Nesse sentido, pensar na tríade "Decolonialidade, Direitos Humanos e Educação" se funda nas emergencialidades espaçotemporais que há na contemporaneidade, a qual é marcada por profunda discussão nos mais diversos campos - epistemológico, político, econômico, cultural, educacional - acerca do paradigma científico, sobre o qual Boaventura de Souza Santos retrata, em Um discurso sobre as ciências, a crise do paradigma dominante à proporção que afirma haver uma nova centralidade no campo das ciências sociais.

As 'verdades científicas' dos componentes curriculares e do currículo escolar precisam coincidir com as verdades do real social, experenciado por todos na escola (docentes, discentes), a fim de as identidades profissionais não entrarem em crise e de evitar que surjam (ressurjam) questionamentos sobre o que consiste a educação. Reflexões permeadas tanto pela ampla discussão dos desafios da formação docente na contemporaneidade quanto por teorizações contemporâneas, somada a inúmeros tensionamentos a respeito do protagonismo juvenil, têm ocupado constantemente espaços acadêmicos e contextos escolares e educacionais. Diante dessa realidade, não raro é pauta de discussões dos eventos educacionais voltados à Formação de Professores o modelo reducionista de aulistas de que fala Arroyo (2013), há muito ultrapassado, visto que este modelo dificulta ou não permite que a realidade social dos estudantes entre e se torne parte da sala de aula.

Torna-se urgente superar o atual modelo de ensino, padronizado e teorizado demais, que atende precário e parcialmente ou sequer atende às demandas locus-regionais, pois outras noções, conceitos e práticas na contemporaneidade, advindos de locais subalternizados, fazem-se presentes e potencialmente aplicáveis.

Dessa forma, o artigo divide-se em três partes e utiliza-se o procedimento metodológico bibliográfico-investigativo, delimitado geograficamente na microrregião do Litoral Norte do Rio Grande do Sul, uma vez que, assentado em análises do cotidiano escolar e da bibliografia pretendese realizar um estudo e reflexão teórica sobre os espaços institucionais da escola e ações propositivas para superar o currículo vigente, com vista a compreender acerca da concepção de 
currículo adotada pela escola, e se tal concepção garante ou não uma práxis educativa relevante no que tange à função social na formação integral do indivíduo. Para tanto, propõe-se a uma análise que busca compreender a relação de aproximação/distanciamento no campo teórico-documentallegal e na fala dos ethos, considerando o advento da decolonialidade na construção do currículo na lógica do pertencimento e do reconhecimento. Enquanto delimitação temporal o recorte utilizado nessa reflexão compreende o período de 2015, 2016 e 2017 em face ao acesso e disponibilidade das fontes.

Aspectos sócio-históricos da realidade escolar e educacional no Litoral Norte/Rio Grande do Sul

Por ser um direito fundamental de natureza social, previsto em lei, o direito à educação está institucionalmente condicionado a uma série de aspectos, tais como princípios e objetivos que o informam, os deveres de cada ente da Federação para com a sua garantia. Por conseguinte, efetivar as políticas públicas requer por parte do gestor público - e os segmentos envolvidos conhecimento sobre os dispositivos legais, bem como do contexto socioeconômico quanto das condições de onde se dá o processo de ensino e de aprendizagem, visto que os resultados obtidos estão intimamente ligados a fatores internos e externos à Escola.

De acordo com o censo do Inep, eram 57.540 mil alunos matriculados em 329 estabelecimentos de ensino na Educação Básica no Litoral Norte ${ }^{1}$, em 2017. Desse número, a Educação Infantil conta com 207 estabelecimentos (Creche, Pré-escola), o Ensino Fundamental soma 188 (Anos iniciais e Anos Finais) e o Ensino Médio 38 unidades (Ensino Médio Propedêutico, Ensino Médio Normal/Magistério e Curso Técnico Integrado/Ensino Médio Integrado). Incluindo matrículas referentes às redes pública e privada, nas duas etapas do ensino básico, 36.313 foram efetivadas nos municípios mais populosos - Capão da Canoa, Tramandaí, Osório, Torres e Imbé -, isto é, o número corresponde a 63,10\% dos alunos matriculados. (INEP, 2017)

Esses cinco municípios também concentram boa parte dos estabelecimentos de ensino da educação básica, os quais atendem, além da população permanente, a um contingente de alunos oriundos da população flutuante, sazonal e/ou temporária, ou seja, que se instala nos centros urbanos localizados à beira mar em períodos fora da alta temporada - à exceção de Osório, com uma escola apenas na faixa de praia, no Distrito de Atlântida Sul². Mampituba, Itati, Três Forquilhas, Morrinhos do Sul e Dom Pedro de Alcântara (com população inferior a 5 mil 
habitantes), localizados na encosta da serra, são os municípios que correspondem juntos a somente $3,51 \%$ do total no número de matrículas na região - ou 2.021 alunos matriculados no período.

O número de matrículas (com a sua respectiva porcentagem) nas duas etapas do ensino básico público, em 2017, corresponde a 44,28\% (ou quase a metade) estão nos Anos Iniciais e 36,35\% nos Anos Finais do Ensino Fundamental, com irrisórios 19,37\% no Ensino Médio. (INEP, 2017)

Se o tema políticas públicas educacionais e sociais - alicerçada em estudos científicos - não entrar na pauta política, a região estará fadada, num futuro próximo, a conviver mais intensamente com situações de extrema vulnerabilidade social (hoje administrável), potencializada pelo analfabetismo. Muitas crianças que iniciam a vida escolar por motivos diversos (trabalho, discriminação, violência, para citar alguns) evadem antes mesmo de completar a primeira etapa do ensino básico. Um cenário é alarmante: a título de reflexão, o número de matrículas que se apresenta no Ensino Médio é por demais aquém do efetivadas nos Anos Iniciais do Ensino Fundamental, déficit este que, em parte, pode estar explicando o grande percentual de analfabetos acima de 25 anos no Litoral Norte. Aliás, quando se analisa tais números, acentua-se a discrepância e a realidade se mostra bem mais assustadora do que parece: dos 25.481 alunos que ingressaram em 2017 nos Anos Iniciais do Ensino Fundamental, em torno de 56\% desses (hipoteticamente) devem figurar na estatística dos que não chegam a frequentar a etapa final do ensino básico, em decorrência da sua condição socioeconômica.

Segundo relatório final do Plano Estratégico Participativo de Desenvolvimento Regional do Corede Litoral do Rio Grande do Sul, elaborado pelo Conselho Regional de Desenvolvimento do Litoral Corede Litoral (2017), a população considerada fixa, ano após ano, cresce consideravelmente na microrregião norte-litorânea, reflexo de dois processos migratórios:

O primeiro caracterizado por famílias de maior renda que vêm ao litoral em busca de um conforto e lazer após sua aposentadoria. Outro grupo, muitas vezes em situações de vulnerabilidade bem grande, são aquelas famílias que anualmente no início do período de veraneio vêm ao litoral em busca de oportunidades de emprego e que acabam se fixando nos municípios muitas vezes de forma irregular. $O$ segundo grupo de migração, famílias que buscam emprego temporário, demanda inúmeras serviços públicos como saúde, habitação e educação. (COREDE Litoral, 2017, p.98)

À proporção que aumenta o contingente de habitantes, índices preocupantes na área de educação, abaixo da média do Estado, evidenciam-se. Com uma taxa de analfabetismo grande, é de se preocupar com os atuais déficits de escolas infantis e a falta de um programa de Educação de Jovens e Adultos de forma mais estruturada e a precariedade no transporte escolar. (COREDE 
Litoral, 2017, p.98) Em situação de vulnerabilidade social na sua cidade de origem, sem perceptivas de vida, famílias inteiras procuram o litoral na busca por empregos. Distorção idade-série de crianças e de adolescentes e adultos com baixa escolaridade (quando não analfabetos) são entraves a gestores que se esforçam para qualificar a educação no seu município. A evasão e a repetência, pelo que se tem apurado, também preocupam as autoridades locais, já que impactam nos índices do Ideb. O crescimento populacional impulsiona o aumento no número de matrículas, invariavelmente.

Do total de matrículas efetuadas na região, 32.689 (ou 56,82\%) foram em Capão da Canoa, Tramandaí, Osório e Torres, com acentuado predomínio na zona urbana, banhada pelo mar. Para se ter uma ideia do quanto é expressivo esse número, os respectivos municípios atenderam no Ensino Médio a 6.685 alunos, correspondendo a 59,98\%; nos Anos Finais do Ensino Fundamental a 11.580, ou 55.36\%; e nos Anos Iniciais do Ensino Fundamental a 14.434, ou 56.64\%. (INEP, 2017)

Os cinco municípios de menor população - Dom Pedro de Alcântara, Morrinhos do Sul, Três Forquilhas, Itati e Mampituba, geograficamente ocupando os territórios da encosta da serra concentram somente 10,99\% do total de matrículas, ou 2.017, incluindo as duas etapas do ensino básico, distribuídas da seguinte forma: 3,3\% no Ensino Médio, 3,87\% nos Anos Iniciais e 3,82\% nos Anos Iniciais do Ensino Fundamental.

Considerando que a maior parte da população fixa norte-litorâneo reside nos centros urbanos, mais especificamente nas cidades e balneários localizados na faixa de praia, predominantemente no locus-periférico, é visível que as pessoas convivam com todos os substratos relativos à vulnerabilidade social. Assim, as crianças e os adolescentes, bem como os adultos que retornam aos estudos, e "indissociáveis do meio" onde se inserem contemporaneamente, desfilam as suas realidades, as suas identidades, os seus pertencimentos, os seus empoderamento, diferentes quanto às matrizes culturais; e que mesmo cerceadas rompem com o silenciamento do corpo e da voz, legitimando, logo, as múltiplas representatividades corporais socioculturais e estéticas, e a escuta.

No tocante as matrículas efetuadas, em 2017, e da sua porcentagem nas zonas urbana e rural, constata-se que há mais alunos matriculados na zona urbana, mas o que não significa estarem frequentando a escola. Por ser obrigatoriedade dos municípios a oferta do ensino nos anos iniciais e finais do Ensino Fundamental, a porcentagem de matrículas na zona rural não difere muito da zona urbana, isto é, $58 \%$ e $38 \%$ contra $43 \%$ e 36\%, respectivamente. Sabe o que isso significa: que as crianças estão frequentando as escolas localizadas nas comunidades onde residem, ou próximas 


\section{Dialogia}

WENCZENOVICZ, Thaís Janaina; COSTA, Anderson Alves. Educação e Direitos Humanos: perspectivas decoloniais desde o litoral norte do Rio Grande do Sul

a essas. No entanto, inverte-se a lógica no Ensino Médio. O número de matrículas acentua-se na zona urbana com 21\%, contra 6\% na zona rural; tal discrepância decorre em virtude de as escolas que ofertam a respectiva etapa estarem instaladas na sede dos municípios.

Entre os anos de 2015 e 2017, pode-se observar nas duas tabelas a seguir que a variação no número de matrícula não é significativa na região. Com relação ao Ensino Médio, na zona urbana, por exemplo, nota-se uma queda de 3,79\% de 2015 para 2016, um pontual aumento de $0,54 \%$ de 2016 para 2017. Já na zona rural não houve variação entre 2015 e 2016, e acréscimo de 7,98\% em 2017, com destaque para Mampituba - saltando de 65 matrículas, em 2015, para 81, em 2017, ou com um percentual de $19,75 \%$ de aumento.

Tabela 1 - Variação do No de Matrículas no Ensino Médio entre 2015 e 2017

\begin{tabular}{|c|c|c|c|c|c|c|}
\hline \multirow{4}{*}{$\begin{array}{l}\text { Municípios da } \\
\text { Microrregião do } \\
\text { Litoral Norte do } \\
\text { Rio Grande do Sul } \\
\text { - COREDE Litoral }\end{array}$} & \multicolumn{6}{|c|}{ Número de Matrículas no Ensino Médio } \\
\hline & \multicolumn{6}{|c|}{$\begin{array}{l}\text { Localização } \\
\end{array}$} \\
\hline & \multicolumn{3}{|c|}{ Urbana } & \multicolumn{3}{|c|}{ Rural } \\
\hline & 2015 & 2016 & 2017 & 2015 & 2016 & 2017 \\
\hline Arroio do Sal & 309 & 304 & 317 & - & - & - \\
\hline Balneário Pinhal & 401 & 362 & 386 & - & - & - \\
\hline Capão da Canoa & 1.899 & 1.837 & 1.868 & - & - & - \\
\hline Capivari do Sul & 174 & 194 & 181 & - & - & - \\
\hline Caraá & 203 & 211 & 206 & - & - & - \\
\hline Cidreira & 358 & 350 & 355 & - & - & - \\
\hline Dom P. de Alcântara & 81 & 85 & 61 & - & - & - \\
\hline Imbé & 756 & 722 & 664 & - & - & - \\
\hline Itati & 66 & 71 & 68 & - & - & - \\
\hline Mampituba & - & - & - & 65 & 58 & 81 \\
\hline Maquiné & 186 & 195 & 191 & 44 & 40 & 40 \\
\hline Morrinhos do Sul & 97 & 76 & 71 & - & - & - \\
\hline Mostardas & 320 & 294 & 361 & 87 & 98 & 92 \\
\hline Osório & 2.259 & 2.110 & 1.985 & - & - & - \\
\hline Palmares do Sul & 229 & 225 & 306 & - & - & - \\
\hline Terra de Areia & 302 & 292 & 314 & - & - & - \\
\hline Torres & 1.364 & 1.319 & 1.291 & - & - & - \\
\hline Tramandaí & 1.422 & 1.426 & 1.491 & - & - & - \\
\hline Três Cachoeiras & 383 & 340 & 345 & - & - & - \\
\hline Três Forquilhas & 83 & 92 & 86 & - & - & - \\
\hline Xangri-lá & 393 & 367 & 384 & - & - & - \\
\hline Litoral Norte & 11.285 & 10.872 & 10.931 & 196 & 196 & 213 \\
\hline
\end{tabular}

Fonte: INEP, 2017.

Quanto ao número de matrículas nos Anos Finais do Ensino Fundamental, de 2015 para 2017, houve aumento de 17.653 para 18.650, na zona urbana, e de 2.164 para 2.265, na rural. Respectivamente, aumentos de 5,35\% e de 4,45\%. Nos quatro municípios com maior número de matrículas - Capão da Canoa, Tramandaí, Osório e Torres -, avolumaram-se as matrículas. 


\section{Dialogia}

WENCZENOVICZ, Thaís Janaina; COSTA, Anderson Alves. Educação e Direitos Humanos: perspectivas decoloniais desde o litoral norte do Rio Grande do Sul

Tabela 2 - Variação no Nº de Matrículas nos Anos Finais entre 2015 e 2017

\begin{tabular}{|c|c|c|c|c|c|c|}
\hline \multirow{4}{*}{$\begin{array}{c}\text { Municípios da } \\
\text { Microrregião do Litoral } \\
\text { Norte do Rio Grande do } \\
\text { Sul - COREDE Litoral }\end{array}$} & \multirow{2}{*}{\multicolumn{6}{|c|}{ Número de Matrículas no Ensino Fundamental/Anos Finais }} \\
\hline & & & & & & \\
\hline & \multicolumn{3}{|c|}{ Urbana } & \multicolumn{3}{|c|}{ Rural } \\
\hline & 2015 & 2016 & 2017 & 2015 & 2016 & 2017 \\
\hline Arroio do Sal & 500 & 543 & 577 & 61 & 51 & 79 \\
\hline Balneário Pinhal & 762 & 841 & 868 & - & - & - \\
\hline Capão da Canoa & 3.167 & 3.369 & 3.436 & - & - & - \\
\hline Capivari do Sul & 263 & 254 & 254 & - & - & - \\
\hline Caraá & 192 & 215 & 263 & 201 & 201 & 170 \\
\hline Cidreira & 898 & 898 & 949 & - & - & - \\
\hline Dom P. de Alcântara & 101 & 121 & 120 & 15 & 13 & 6 \\
\hline Imbé & 1.087 & 1.148 & 1.165 & 148 & 181 & 167 \\
\hline Itati & 124 & 111 & 107 & 67 & 82 & 83 \\
\hline Mampituba & 94 & 111 & 103 & 81 & 78 & 67 \\
\hline Maquiné & 207 & 212 & 203 & 205 & 217 & 202 \\
\hline Morrinhos do Sul & 65 & 70 & 75 & 77 & 91 & 88 \\
\hline Mostardas & 648 & 688 & 690 & 202 & 201 & 195 \\
\hline Osório & 2.191 & 2.277 & 2.283 & 255 & 289 & 297 \\
\hline Palmares do Sul & 426 & 440 & 488 & 204 & 194 & 204 \\
\hline Terra de Areia & 725 & 608 & 578 & - & - & - \\
\hline Torres & 1.739 & 1.798 & 1.805 & 439 & 444 & 469 \\
\hline Tramandaí & 3.052 & 3.147 & 3.218 & - & - & - \\
\hline Três Cachoeiras & 436 & 443 & 438 & 172 & 177 & 163 \\
\hline Três Forquilhas & 73 & 81 & 85 & 98 & 82 & 75 \\
\hline Xangri-lá & 903 & 963 & 945 & - & - & - \\
\hline Litoral Norte & 17.653 & 18.338 & 18.650 & 2.164 & 2.301 & 2.265 \\
\hline
\end{tabular}

Fonte: INEP, 2017.

Além da emergencialidade para dar importância às avaliações, pesquisas e análises no sentido de aferir a eficácia das políticas públicas educacionais e apontar caminhos permanentes de aprimoramento, tanto os educadores e os coordenadores pedagógicos quanto os gestores públicos precisam se familiarizar com os números oficiais do governo sobre a educação e o perfil socioeconômico. Invariavelmente, o currículo escolar é pensado e organizado com base em concepções incutidas pelo momento histórico, acrescido de posições teóricas, educacionais e políticas. Afirmar que a educação e as políticas sociais dependem de uma boa qualidade da gestão pública é atestar o que já ocorre na práxis de países nórdicos ${ }^{3}$, excelência em justiça social. Logo, o Plano Nacional de Educação (PNE) depende da qualidade de quem faz as políticas municipais, estaduais.

Por conseguinte, é oportuno que todos os segmentos envolvidos na tessitura reconheçam a realidade escolar da instituição, do bairro, da cidade e do município onde se insere; realidade do aluno e de sua família; bem como investigar a realidade educacional, para então construí-lo com base nos direitos humanos e nos direitos fundamentais, e assim assegurar o direito para a educação 
(inerente à natureza do homem, que precede a própria natureza do Estado), uma vez que é um instrumento fundamental para que o homem se realize como tal.

\section{Atravessamentos histórico-culturais em perspectiva local}

Anterior ao processo de colonização e povoamento o Litoral Norte do Rio Grande do Sul era habitado por diversas populações indígenas. Posteriormente adentraram no território várias nacionalidades (imigrantes) nos séculos XIX e XX. Embora cultuada pelo sentimento de açorianidade 4 por parte da historiografia regional, destaca-se a microrregião do Litoral Norte do Rio Grande do Sul em virtude da sua diversidade e atravessamentos étnico e cultural ao longo de séculos, intensificando com a chegada dos povos europeus e de matriz africana. Contudo, da encosta da serra à beira mar, foi o indígena o primeiro protagonista da ocupação e formação histórica dessa região, fixados à beira das águas doces, próximos aos rios e às diversas lagoas, e das águas salgadas, na faixa litorânea de Torres (ao norte) a Mostardas (ao sul). Assim, de igual modo, os povos indígenas, os representantes do colonialismo, o negro e os imigrantes deixaram de legado contributos quanto a usos e costumes.

Mesmo que, no passado, tenha se destacado enquanto território de inúmeros fatos e acontecimentos históricos $^{5}$ - e muito contribuído para compor a história sul-rio-grandense - o Litoral Norte, apesar de atrair um grande contingente de pessoas com poder de compra e consumo na temporada de veraneio, registra segundo índices que uma parte de sua população está em situação de vulnerabilidade social, tanto na zona urbana quanto na zona rural. Conforme o relatório do COREDE Litoral (2016), entre 2000 e 2016, houve um expressivo crescimento populacional, aumentando de 243.411 para 334.107 habitantes. A população fixa foi de 332.431 habitantes, em 2017 (COREDE, 2017), ou seja, mais de 80\% das pessoas residindo nas áreas urbanas, com 49,5\% desse montante ocupando cidades à beira mar.

Os deslocamentos populacionais dos municípios interioranos aos municípios banhados pelo mar sempre existiram, e incidem culturalmente sobre os locais onde as pessoas passam e, em especial, aonde chegam - seja optando por uma pausa em suas trajetórias, seja ao construir suas moradas. A mobilidade humana é fator de desenvolvimento e de transformação social, cultural e econômico. O modo de viver das pessoas que nasceram no Litoral Norte sofreu alterações devido aos contemporâneos atravessamentos culturais e, de certa forma, até descaracterizando aspectos identitários locus-regionais. Tanto os atravessamentos culturais de outrora quanto os contemporâneos podem servir de laboratório de interação, de integração e também de superação 
das diferenças, que apesar de suscitar tensões, enriquece-nos, uma vez que o aprendizado na convivência é mútuo.

Formada por 21 municípios, o Litoral Norte ${ }^{6}$ se diferencia das demais regiões do Estado por atrair a população flutuante, sazonal e/ou temporária, muito em razão do patrimônio natural locus-regional - principalmente, de dezembro a março, período da alta temporada, atraída pelo sol e o mar, que nela permanece "por alguma fração de tempo (embora essa população seja predominantemente de veranistas e turistas, também inclui trabalhadores, pessoas que estejam visitando familiares, entre outras).” (ZUANAZZI; BARTELS, 2016, p. 5-6) A maioria dos núcleos familiares que chega de maneira sazonal opta por residir nele, principalmente nos cinco municípios mais populosos - quatro banhados pelo mar.

Embora em menor número, os municípios com sede à beira mar (Tramandaí, Capão da Canoa, Tramandaí, Torres, Cidreira, Imbé, Xangri-Lá, Balneário Pinhal, Arroio do Sal) são os que mais apresentaram taxa de crescimento demográfico no período, sendo o fator preponderante a vinda de pessoas de outras regiões do Estado em busca de emprego nos setores gastronômico e da construção civil. Os dez municípios na encosta da serra (Osório, Caraá, Maquiné, Itati, Terra de Areia, Três Cachoeiras, Três Forquilhas, Morrinhos do Sul, Dom Pedro de Alcântara, Mampituba) e os três na planície da Lagoa dos Patos (Palmares do Sul, Capivari do Sul e Mostardas) também cresceram, mas não significativamente.

\section{Educação e Direitos Humanos: mediação e reflexão em perspectivas decoloniais}

Práticas pedagógicas amparadas na educação em Direitos Humanos que mesclem currículos para trazer à luz do contexto escolar, quer seja nas escolas formais, quer seja nas não formais - é cada vez mais urgente. Trata-se da postura que procura abolir a visão colonial e universalista, ou seja, a imposição de uma cultura eurocêntrica, rompendo com as práticas excludentes nos espaços escolares. Embora significativos avanços no campo educacional tenham ocorrido nas três últimas décadas, conforme estudos e pesquisas acadêmicas e institucionais, o atual sistema brasileiro de ensino nem sempre dialoga com tempo presente. Dessarte, constantes reformas educacionais vem sendo implementadas em todo o território nacional, nas esferas municipal, estadual e federal, propondo uma prática pedagógica vinculada à realidade do sujeito o qual deve ser compreendido enquanto ente histórico, social, cultural e de direito. Todavia, tais reformas assentam-se quase que exclusivamente em buscar novas práticas pedagógicas para tãosomente repaginar currículos, sem reflexionar a educação por meio de novas epistemes e entrelaçamentos temáticos, a exemplo dos Direitos Humanos. 
Para saber quanta coisa não se sabe, antes de conhecer o instituído é preciso reconhecerse, pois apenas assim os discursos produzidos pelos sujeitos não serão abstratos tampouco desprovidos de consciência de si. Aliás, é fundamental entender que não há docência sem discência (FREIRE, 1996), e exercer a prática educativo-crítica é insurgir e, subversivamente, promover o desfronteiramento curricular (ação mais difícil de ocorrer em escolas formais, historicamente alicerçadas sob a base da matriz eurocêntrica) em prol dos saberes socialmente construídos. Face ao exposto, o educador e filósofo brasileiro Paulo Freira questiona:

Por que não discutir com os alunos a realidade concreta a que deva associar a
disciplina cujo conteúdo se ensina, a realidade agressiva em que a violência é a
constante e a convivência das pessoas é muito maior com a morte do que a vida?
Por que não estabelecer uma "intimidade" entre os saberes curriculares
fundamentais aos alunos e a experiência social que eles têm como indivíduos?
Por que não discutir as implicações políticas e ideológicas de um tal descaso dos
dominantes pelas áreas pobres da Cidade? A ética de classe embutida neste
descaso. Porque, dirá um educador reacionariamente pragmático, a escola não
tem nada que ver com isso. A escola não é partido. Ela tem que ensinar os
conteúdos, transferi-los aos alunos. Aprendidos, estes operam por si mesmos.
(FREIRE, 1996, p. 30)

Nesse cenário pergunta-se: como implementar uma pedagogia decolonial baseada nos pressupostos do Pensamento Decolonial latino-americano, em conformidade com a legislação e com os documentos educacionais? Primeiramente, é preciso que professores e demais profissionais da educação que atuam nas escolas norte-litorâneas de ensino formal reconheçam que a maioria dos conteúdos hoje distribuídos na instância curricular decorre de uma perspectiva eurocêntrica de conhecimento, e que há muito os mesmos não dão conta dos desafios e perspectivas dos processos educativos em tempos de pós-contemporaneidade. Com base nessa assertiva, sugere-se reflexionar a conjuntura do currículo vigente em face aos conceitos de interculturalidade, ecologia dos saberes e epistemologias do Sul.

Pensar/ressignificar a escola e as práticas educativas na contemporaneidade permeia o viés dos novos significados epistemológicos da Educação. Existe uma colonialidade do poder e saber, entendida tanto como resultado da construção no interior da modernidade de forma econômicopolítica como educacional na América Latina e, especialmente, no Brasil. Razão esta que leva à necessidade de olhar o processo educativo pela perspectiva da dependência e da subalternização de inúmeros grupos sociais. Investir na tessitura de um currículo apartado do projeto global de modernização e colonialidade é fundamental, mas requer estudo por parte dos envolvidos, para assim assimilar a necessidade de construir um conhecimento outro, que considere todas, enfim, as formas de produção do conhecimento, e não apenas o validado pela ciência. 
Proposituras em e para uma Educação em Direitos Humanos na perspectiva decolonial pressupõe um ensino no qual "o coletivo está nas vozes" dos sujeitos que narram, contam e dão presença ao como fazer-pensar-lutar (WALSH, 2009). Assim, investir na pesquisa como princípio educativo, nas duas etapas do ensino básico, conforme preconizam os Parâmetros Curriculares Nacionais, pode ser um mo(vi)mento na "escola pública formal” a fim de superar o clássico sistema conteudista e vertical, a partir do qual sujeitos assumem-se protagonistas - e não mais mero coadjuvante que assimila estruturas, esquemas, e/ou reproduz as etapas dos processos metodológicos da investigação científica - e transformam-se, assim, "em reais sujeitos da construção e da reconstrução do saber ensinado, ao lado do educador, igualmente sujeito do processo".

A Base Nacional Comum Curricular (BNCC) destaca nas competências gerais a necessidade de exercitar a empatia, o diálogo, a resolução de conflitos e a cooperação, fazendo-se respeitar e promovendo o respeito ao outro e aos direitos humanos, com acolhimento e valorização da diversidade de indivíduos e de grupos sociais, seus saberes, identidades, culturas e potencialidades, sem preconceitos de qualquer natureza. (BNCC, p.9)

Reforça ainda que para a constituição da nova (des)ordem mundial e a emergência da globalização/mundialização, assim como suas consequências é relevante reconhecer a interculturalidade dos povos e nações. Por conta do estudo do papel da Europa na dinâmica econômica e política, é necessário abordar a visão de mundo do ponto de vista do Ocidente, especialmente dos países europeus, desde a expansão marítima e comercial, consolidando o Sistema Colonial em diferentes regiões do mundo. É igualmente importante abordar outros pontos de vista, seja o dos países asiáticos na sua relação com o Ocidente, seja o dos colonizados, com destaque para o papel econômico e cultural da China, do Japão, da Índia e do Oriente Médio. Entender a dimensão sociocultural e geopolítica da Eurásia e das Américas na formação e constituição do Estado Moderno e nas disputas territoriais possibilita uma aprendizagem com ênfase no processo geo-histórico, ampliando e aprofundando as análises geopolíticas, por meio das situações geográficas que contextualizam os temas da geografia regional. (BNCC, 2017, p.381)

De forma objetiva, pode-se apontar que os currículos das escolas públicas do Litoral Norte não contemplam a diversidade étnica e cultural da ocupação/formação do território nortelitorâneo, tampouco reconhece a existência de atravessamentos culturais contemporâneos. Com o intuito de consolidar uma proposta de educação que permita o diálogo entre os conhecimentos científicos e os saberes ancestrais e organizações sociais próprias do grupo que representa, o Rio Grande do Sul implementou, em 2017, o Plano Estadual de Implementação das Diretrizes 
Curriculares Nacionais para a Educação das Relações Étnico-Raciais (em consonância com a Lei Federal 11.645, que visa a trabalhar conteúdos da história e cultura afro-brasileira e dos povos indígenas brasileiros) é mais um dispositivo legal que busca a interculturalidade nos espaços escolares.

Além do seletivo contexto escolar, outras lógicas educativas estão presentes nas comunidades quilombola e indígena: a ancestralidade, a tradição oral, a cultura corporal, o trabalho; bem como a resistência, a luta pelos direitos, posicionamentos latentes contra o modelo social, político e cultural da modernidade/colonialidade que vigora. Os sujeitos que advêm dessa organização social e política possuem em seus corpos saberes, relacionados a essa vivência, que para eles são fundamentais, pois revelam a sua identidade e pertencimento e produzem a continuidade do seu grupo. Por isso, a emergência de um currículo e de uma educação escolar baseada na perspectiva intercultural (WALSH, 2009).

Há em curso uma crise epistemológica a qual se torna terreno fértil às novas tendências do conhecimento científico (CHARTIER, 2002, p. 81). Na emergência por uma pedagogia e um pedagógico decolonial que vise aos protagonismos educativos e à cidadania, e que, por meio de tensionamentos e de dinâmicas interdisciplinares, aponte os desafios e os caminhos a tomar a fim de transformar a realidade na qual se inserem os sujeitos, nem sempre orquestramos as mudanças necessárias, visto que, quando vivemos tempos de incerteza, abandonar os paradigmas dominantes tornam-se ainda mais difíceis.

Cabe ressaltar que, ao se posicionar contra as várias formas de dominação, exclusão e discriminação na contemporaneidade, populações quilombola e indígena se deparam com desafios de toda ordem para legitimar e implementar na educação básica um currículo decolonial, sobretudo pela carência e pelo descaso dos gestores para com as políticas públicas de promoção e defesa dos Direitos Fundamentais Sociais. Na dimensão curricular das escolas públicas do Litoral Norte pouco ou nada dessas etnias se percebe, situação preponderante para aumentar o preconceito e a discriminação étnico-racial. Em oposição a tais práticas de opressão, emanam na política educacional brasileira propostas válidas de reconhecimento dos saberes indígenas, quilombolas e da população africana e afro-brasileira ${ }^{7}$. Em suma, pode-se dizer que as ações afirmativas são instrumentos vitais para assegurar a essas populações uma educação diferenciada e que respeite suas organizações sociais, culturais e históricas.

Reconhecer - e por em pauta - as diversas demandas dos segmentos sociais brasileiros significa colaborar com o processo de emancipação/pertencimento, bem como tensionar os vários processos que se propõem a minimizar a subalternização das populações originárias e comunidades 
tradicionais por um saber hegemônico, principalmente no currículo e nos materiais didáticos, nas escolas localizadas dentro de territórios específicos. Parte do pressuposto de que a organização curricular oficial ignora o conhecimento e os saberes das populações tradicionais, reproduzindo a instrução convencional como modelo do sistema educacional, cuja realidade também se observa na microrregião do Litoral Norte do Rio Grande do Sul, embora a forma de pensar a contemporaneidade e pensar-se hoje ocupe espaços na academia.

Portanto, implementar políticas públicas sócio/interculturais de forma efetiva requer estudos e planejamento a médio e longo prazos, e posturas apartidárias. É preciso que gestores, educadores e sociedade civil conheçam as reais necessidades locus-regionais para demarcar o perfil microrregional acerca dos aspectos histórico, étnico, cultural, econômico, demográfico, socioambiental, etc. Para isso, romper com a história de cunho tradicional em favor de uma história problematizadora é preciso, a fim de buscar os sem reconhecimento, "aqueles sem rastros" (FOUCAULT $\left.^{8}, 1992,1995,2001\right)$. Os protagonismos educativos serão alcançados se a Escola, enquanto locus privilegiado, decolonizar-se, romper com a verticalidade, e assim preservar as narrativas a partir do reconhecimento dos saberes e conhecimentos historicamente subjugados pela epistemologia dominante.

\section{Conclusão}

São inúmeras as áreas do conhecimento e segmentos da sociedade civil organizada que analisam e discutem a relação entre a educação e os Direitos Humanos. Adequar-se às novas problematizações, temáticas e conhecimentos que se acentuam para marcar discursos é fundamental. Historicamente, a educação foi relegada ao segundo plano quando se trata de debates e demandas coletivas; negada às decisões políticas por séculos, coube aos coletivos invisibilizados e vulnerabilizados demandar espaços ao longo da trajetória histórica para sair de uma posição de obediência e resignação

Para tanto, é fundamental rupturas teórico-metodológicas para avançar nas discussões que visam construir uma sociedade mais cidadã, em conformidade com os Direitos Humanos. Sugestiona-se que essa efetivação pode iniciar por meio de formação docente continuada e da elaboração de material didático-pedagógico onde aspectos locus-regionais de cunho históricogeográfico, étnico/cultural, social, educacional, econômico e outros sirvam de referência à tessitura desse currículo na busca por uma educação que priorize a cidadania e os protagonismos educativos, alicerçada nos Direitos Humanos. 
No tocante a locus-regional analisado é possível indicar que o mesmo reconhece a diversidade étnica e sócio-cultural de sua composição, entretanto a práxis pedagógica nem sempre acompanha ou reconhece essa diversidade no cotidiano da escola. Afrodescentes, indígenas, refugiados e outras categorias não raro são reconhecidos em práticas pontuais dos professores. Esses geralmente atuam e desenvolvem olhares sobre 'outros' currículos por iniciativa individual que como uma prática inclusiva.

\section{Referências}

ARROYO, Miguel G. Currículo, território em disputa. - 5. ed. - Petrópolis, RJ: Vozes, 2013.

BRASIL. Plano Nacional de Educação 2014-2024: Lei no 13.005, de 25 de julho de 2014, que aprova o Plano Nacional de Educação (PNE) e dá outras providências. - 2 ed., reimpr. - Brasília: Câmara dos Deputados, Edições Câmara, 2017.

BRASIL. Constituição. República Federativa do Brasil de 1988. Brasília, DF: Senado Federal, 1988. Disponível em: <http://www.planalto.gov.br/ccivil_03/Constituicao/Constituicao.htm>. Acesso em: 21 Jan. 2020.

BRASIL. Ministério da Educação. Ideb: apresentação. Disponível em: http://portal.mec.gov.br/conheca-o-ideb. Acesso em: 20 Jan. 2020.

BRASIL. Inep/MEC. Metas educacionais: O que são as metas de qualidade educacional. Disponível em: http://portal.inep.gov.br/metas-educacionais. Acesso em: 20 Jan. 2020.

BRASIL. Inep/MEC. Indicadores Educacionais do Censo Escolar 2017 estão disponiveis para consulta. Disponível em: http://portal.inep.gov.br/artigo/-

/asset_publisher/B4AQV9zFY7Bv/content/indicadores-educacionais-do-censo-escolar-2017estao-disponiveis-para-consulta/21206. Acesso em 19 Jan. 2020.

BRASIL. Base Nacional Comum Curricular. Brasília, 2017. Disponível em:

$<$ http://basenacionalcomum.mec.gov.br/wp-

content/uploads/2018/06/BNCC_EI_EF_110518_versaofinal_site.pdf. Acesso em: 02 Mar. 2020.

CONSELHO Regional de Desenvolvimento do Litoral Corede Litoral. Plano Estratégico

Participativo de Desenvolvimento Regional do Corede Litoral do Rio Grande do Sul (Relatório final). Osório:

COREDE Litoral, 2017. Disponível em:

https://planejamento.rs.gov.br/upload/arquivos/201710/09144219-plano-litoral.pdf. Acesso em: 26 Jan. 2020.

CHARTIER, Roger. O mundo como representação. In: À beira da falésia: a bistória entre incertezas e inquietude. Trad. Patrícia Chittoni Ramos.Porto Alegre: Ed. Universidade/UFRGS, 2002.

FOUCAULT, Michel. Microfísica do poder. Rio de Janeiro: Graal, 1992. 
FREIRE, Paulo. Pedagogia da Autonomia. Saberes necessários à prática educativa. 31 ed. São Paulo: Paz e Terra, 1996.

OCDE. Organização para a Cooperação e Desenvolvimento Econômico ou Econômico. Relatórios Econômicos OCDE: Brasil 2018 -Disponível em: https://www.oecd.org/eco/surveys/Brazil-2018-OECD-economic-survey-overviewPortuguese.pdf. Acesso em: 10 Dez. 2019.

ZUANAZZI, Pedro Tonon; BARTELS, Mariana. Estimativas para a população flutuante do Litoral Norte do RS. Porto Alegre: FEE, 2016. Disponível em: https://www.fee.rs.gov.br/wpcontent/uploads/2016/07/20160711relatorio-populacao-flutuante-do-litoral-norte.pdf. Acesso em: 08 Fev. 2020.

WALSH, Catherine. Interculturalidad, Estado, Sociedad: Luchas (de)coloniales de nuestra época. Quito: Universidad Andina Simón Bolivar, Ediciones Abya-Yala, 2009. Disponível em:

$<$ http://www.flacsoandes.edu.ec/interculturalidad/wpcontent/uploads/2012/01/Interculturalidad-estado-y-sociedad.pdf $>$. Acesso em: 15 de Dez. 2019.

Recebido em: 31 jan. 2020/ Aprovado em: 03 mar. 2020

\section{Cite como}

(ABNT NBR 6023:2018)

WENCZENOVICZ, Thaís Janaina; COSTA, Anderson Alves. Educação e Direitos Humanos: perspectivas decoloniais desde o litoral norte do Rio Grande do Sul. Dialogia, São Paulo, n. 35, p. 36-51, maio/ago. 2020. Disponível em: https://doi.org/10.5585/dialogia.n35.16526

\section{American Psychological Association (APA)}

Wenczenovicz, T. J., \& Costa, A. A. (2020, maio/ago.). Educação e Direitos Humanos: perspectivas decoloniais desde o litoral norte do Rio Grande do Sul. Dialogia, São Paulo, 35, p. 36-51. https://doi.org/10.5585/ dialogia.n35.16526.

\footnotetext{
${ }^{1}$ Contabilizam-se escolas das redes municipal, estadual e federal.

2 Escola Municipal de Ensino Fundamental José Paulo da Silva, instalada no centro do balneário, que atende alunos do referido Distrito e da praia de Mariápolis, o balneário vizinho, também pertencente a Osório. Nesta década, terrenos "considerados área verde" do Distrito de Atlântida Sul foram ocupadas por famílias em vulnerabilidade social, vindas de diferentes regiões do Estado, mais precisamente de áreas periféricas de cidades maiores, sem qualquer planejamento. Os professores da escola notaram que o corpo discente não era mais o mesmo, que ano após ano os alunos matriculados traziam outros valores sociais, culturais, históricos. Com base nisso, novas políticas
} 
públicas de ordem social e educacional precisaram ser executadas, para assim assegurar o direito à educação e a cidadania.

${ }^{3} \mathrm{Na}$ Finlândia, 99\% dos jovens concluem o ensino médio, o maior índice global. No Brasil, só 59\% completam essa fase escolar até os 19 anos. Os resultados dos indicadores de Educação pelo PISA (Programme for International Student Assessment), o maior exame internacional do mundo, revelam que os cinco países nórdicos nas provas de múltipla escolha em Ciências, Matemática e Leitura obtiveram resultados positivos. PISA é avaliado trienalmente pela OCDE desde 2000. (OCDE, 2018)

${ }^{4}$ Atribui-se a origem do termo açorianidade ao acadêmico Vitorino Nemésio Mendes Pinheiro da Silva (1901-1978), escrito primeiramente num artigo seu publicado em 1932.

${ }^{5}$ Dentre tantos fatos e acontecimentos, podemos destacar a passagem do botânico francês Auguste de Saint'Hilaire, entre 1820-1821; do Imperador do Brasil D. Pedro I, 1826; cenário de dois episódios de revolução: passagem dos lanchões Farroupilha e Seival, na Revolução Farroupilha, e a Revolução Federalista, em 1895. Em 1808, nasce aqui Manuel Luiz Osorio, Marquês do Herval, Patrono da Arma de Cavalaria do Exército Brasileiro, numa estância próxima à Vila de Conceição do Arroio, onde hoje funciona o Parque Osório, localizado no Município de Tramandaí.

${ }^{6} \mathrm{O}$ respectivo território, que hoje abrange toda a microrregião do Litoral Norte, até meados do século XX, pertencia a um único município, desmembrado do município de Santo Antônio da Patrulha, em 1857: Conceição do Arroio. Em 1934, passa a denominar-se Osório, em homenagem Manuel Luiz Osório. Atualmente, Osório tem seu território bem reduzido por conta das várias emancipações. Das emancipações ocorridas a partir de 1960 - à exceção de Torres, ainda no final do séc. XIX -, são 18 os desmembramentos em sua genealogia, com seis advindos da célula mater: Tramandaí, Capão da Canoa, Palmares do Sul, Terra de Areia, Maquiné e Torres, dos quais municípios já se originaram.

${ }^{7}$ Além da Lei $\mathrm{n}^{\mathrm{o}}$ 10.639/03, a qual decreta a obrigatoriedade do ensino de cultura e história africana e afro-brasileira na educação básica, em 2008, foi sancionada a Lei no 11.645, que também inclui a obrigatoriedade do ensino da história e cultura indígena. Enquanto modalidade da educação básica, a Educação Escolar Indígena é assegurada desde 1999, por meio do Parecer CNE/CEB n 14/99 e da Resolução CNE/CEB no 3/99. Outra modalidade da educação, a Educação Escolar Quilombola, foi estabelecida pela Resolução no 8/2012.

${ }^{8}$ Como forma de esclarecimento teórico, é importante salientar que Michel Foucault, ao se aproximar da Antropologia, preocupa-se em desconstruir o real, e não mais revelá-lo, ao passo que rompe com a noção consolidada de sujeito moderno, afirmando que este não é dotado de uma consciência e de autonomia, mas regulado e produzido pelos discursos de uma época e pelos poderes que visam discipliná-lo. Mostra-se menos preocupado em dar voz aos sujeitos esquecidos pela História, mas em compreender como se produz este silêncio que leva ao esquecimento. 